\title{
The legal regulation of digitalization of some areas of public life in modern theory of State and Law
}

\author{
$1 \mathrm{PhD}$, Associate Professor, Altai State University, Barnaul, Russian Federation. \\ E-mail: kovalenko1288@mail.ru (iD https://orcid.org/0000-0001-6017-8933 \\ 2 Altai State University, Barnaul, Russian Federation. \\ E-mail: kke@email.asu.ru (iD https://orcid.org/0000-0002-8673-8166 \\ 3 Altai State University, Barnaul, Russian Federation. \\ E-mail: kke@email.asu.ru (iD https://orcid.org/0000-0003-3091-990X
}

\author{
Kseniya E. Kovalenko ${ }^{1}$ \\ Daria A. Statsenko ${ }^{2}$ \\ Yulia V. Pechatnova ${ }^{3}$
}

\begin{abstract}
The article discusses the changes in public life associated with digitalization. The article also analyzes the introduction of digital technologies in the transport system of regulation and control of traffic as the progressive direction that allows to answer both socio-economic challenges and national security challenges. The study is based on the study of the experience of using intelligent systems in Russia and abroad, the prospects of further development and improvement of transport infrastructure are considered. The concept of digital law is given, its main features are highlighted. Discussions about the robot implementation in the field of jurisprudence, options for legal regulation of the status of machines with artificial intelligence, as well as the distribution of unmanned vehicles are outlined. The prospects and problems of these processes are analyzed. It is concluded that digitalization will have the constant tendency to increase.

Keywords: Digital law. Digitalization. Robots. Unmanned vehicles. Law.
\end{abstract}

\section{INTRODUCTION}

At present, the high rates of informatization of production, economic and social processes make it possible to talk about the information revolution, affecting, among other things, the motor transport complex, where one of the main directions of informatization is the creation and implementation of intelligent transport systems. Numerous statements by officials on the need to use the latest digital technologies in traffic management confirm the priority position for the development of transport infrastructure in the state policy of Russia.

The high growth of automation leads to global changes both in public life and in the economic sphere. The purpose of the implementation the high technologies is the significant change of human's life, the satisfaction his needs, reduce time costs, and also eliminate such concepts as "ineffective" and "unproductive".

Today it is impossible to imagine the daily human existence without digital devices. The life of any member of modern society is digitized and hosted on various servers. Back in 2000, the II conference "Law and the Internet: Theory and Practice" was held, during which the main sections of digital law were highlighted. Among them, in particular, the right of digital money, the right of digital transactions, the right of digital disputes, the right of software robots, the right of digital public administration, and other rights were named.

After almost 20 years, there is all the reasons to consider that the new direction in our life, the digital space, is actively forming. The law is one of the main branches of social 
sphere. That is why; we are witnessing the formation of the new branch of law - digital law. Now, it seems possible to highlight its main features:

- normativeness (it establishes rules of behavior in the general nature);

- compulsory (its action applies to all or the wide range of subjects);

- guaranteed by the state (it is supported by measures of state coercion);

- intellectual-volitional character (it expresses human's will and consciousness);

- formal certainty (legal norms are expressed in an official form);

- systematic (it is the internally agreed, ordered organism).

Thus, we can conclude that digital law is the system of generally binding, formally defined, guaranteed by the state rules of behavior that develops in the field of application or through the use of digital technology, including through special software.

The emergence of digital law is promoted by the transition to the digital method of communication, recording and data transmission using digital devices. This transition process can be termed the term "digitalization".

\section{DEVELOPMENT}

In the context of creating the digital environment, the discussion about the legal status of robots and, in general, machines with artificial intelligence (including unmanned vehicles), which is gaining momentum and becoming more acute, is important.

It goes without saying that today the robot is the inferior participant in legal relations, since its ability to consciously act is much less in comparison with the human. The explanation for this is the origin of the human and robot. The robot is created and improved by people, while the person is endowed with consciousness from birth. However, it is worth mentioning that there is the certain probability that robots in the certain period will not need in human intervention. In this regard, it is worth noting that in legal science you can find diametrically opposite points of view regarding the legal personality of robots. So, for example, Arkhipov V.V. and Naumov V.B. in their scientific work "About Some Issues of the Theoretical Foundations of the Development the Legislation on Robotics: Aspects of Will and Legal Personality" identifies several approaches in this direction: "the concept of the robot as an animal", "the concept of the robot as the legal entity". The idea of robots as legal entities is in other sources. There is also a concept proposing to consider the robot as an agent.

Of course, giving robots the status of subjects in legal relations will require the radical change in our ideas about law in the conditions of the existence the artificial intelligence.

There are completely different options for legal regulation of the status of machines with artificial intelligence. Recognizing the incapacity of machines, their essential difference from man, it is possible, in principle, to prevent at the legislative level from giving them the status of citizens, that means persons are endowed with personal constitutional rights and duties. In this case, the functioning of such objects should be the responsibility of the persons, who create them, or the entities that own and control artificial intelligence. At the same time, machines with artificial intelligence could be endowed with the limited legal personality in certain conditions by analogy with legal entities. It is possible to recognize such entities as real members of human society only in the distant future.

However, the conclusion that robots and other machines are objects of legal relations and cannot be independent subjects of law seems logical in the current system of legal relations. It is still difficult to imagine that the machine with artificial intelligence can inde- 
pendently, "personally" enter into legal relations and become the subject of legal responsibility.

\section{RESULT.}

In connection with the above, the question of the functioning of robots in the field of legislation and the administration of justice is interesting. Can the computer programs solve litigation and make decisions? Digitalization is designed to make life easier, to get rid of routine and similar work. This is the message that was laid in the framework of the presentation of the LegalApe 2.8 robot. This robot is developed on the basis of neural networks using the array of data, which includes judicial practice, scientific work and the doctrinal position of lawyers. The robot lawyer is able to answer questions, give explanations and participate in debates, using information from regulatory legal acts and authoritative doctrinal sources. It is possible to train the robot - through scientific papers, legal acts, judicial practice, business correspondence of lawyers and training conducted by specialists.

The judicial duel between the robot and the famous lawyer, candidate of legal sciences Roman Bevzenko took place during the St. Petersburg Youth Legal Forum-2018. The dispute between the person and the bot was built on the model of the dispute in arbitration court. First, the parties stated their position, and then there was the stage of questions, after this was the debate.

Communication with the robot was carried out by voice input of information, while the text was duplicated on the screen. However, sometimes the bot incorrectly recognized speech, which led to errors in its texts or answers to questions that were not posed for this. In the debate, the bot often repeated what was already said at the beginning of the match. It is also worth paying attention to the fact that the bot has studied during the dis- pute: in some of its answers there are links to the arguments that Roman Bevzenko has given.

As the result of the match, it become clear that the robot lacks the understanding of the spirit of law, but pays attention to the form of the text.

At the present, the implementation of the artificial intelligence in the legal sphere is only at the beginning. The development of the interaction between the artificial intelligence and humans in arbitration and civil disputes is the matter of dispute. However, it is obvious that neural networks are already the integral part of our legal life future, because "the law has no emotions," says Ekaterina Dukhina, the lawyer and the Member of the Law Chamber of Moscow. Perhaps the "emotionlessness" of both the robot judge and the law enforcer will reduce the likelihood of the incorrect interpretation of the law or the incorrect application of legal norms.

However, today the legislation contains the huge array of norms that must be applied and interpreted from the subjective point of view, using judicial discretion. It goes without saying that the total implementation of artificial intelligence in the field of jurisprudence will require the restructuring of the law. It is also possible that robots can make technical errors (incorrect speech recognition, technical failures, cyber attacks), which can also lead to incorrect application of legal norms.

Of course, it is too early to talk about the possibility of the complete replacement of the person with the robot in the legal profession, but the robot is able to reduce the amount of routine work even today.

Digitalization is actively capturing the motor transport complex, where one of the main areas of informatization is the creation and implementation of the intelligent transport systems.

The experience of different states in the implementation of automatic transport sys- 
tems was studied during the research.

In Singapore, on the roads there are vehicle detectors that are located every 500 meters, as well as video cameras - on every kilometer of tracks, and every traffic light and city bus are equipped with them. Also, each taxi is equipped with devices that allow you to track the location of the car and its speed.

All cars have GPS sensors that collect and send information about movements to the control room. All information received from these funds is collected by the single traffic control center. The green light at the pedestrian crossing is switched on by pressing the button at the traffic lights, and older people or people with disabilities can attach the special card to it, which will increase the time to go to the opposite side. Radio channels are actively used, on which reports on the congestion of key roads and interchanges are transmitted, you can monitor the traffic in online mode.

In another country, Japan, fixed devices and motion sensors are located near the tracks, which help to collect information about situations on motorways at the Traffic Information Center, through which collected and edited data about traffic jams, traffic accidents or repair work are transmitted to navigation systems vehicle users. Information from the road users themselves, who can send it through their mobile devices, is also very important.

The third country, taken as the object for research, was the United States of America. The United States uses the wireless communication channel that allows for emergency warnings for motorists, frontal collision warning, vehicle safety inspection, electronic parking payments, electronic toll collection, sensor data collection, and roll over warning, commercial clearance and vehicle safety. Traffic signs are equipped with LEDs, depending on the time of day and the congestion of the certain section of the road, indicators of different colors turn on.
The fourth country is China. Hong Kong has the unified traffic light control system, which operates using sensor wires located under the asphalt. These wires determine the number of cars accumulated on the road, so the green light starts to burn longer in the direction in which there are more cars.

Often, the green zone is made of several closely spaced roads so that the stream passing through one intersection does not linger on another. Each driver can purchase a special electronic program that contains an interactive road map with all street signs and special signals, as well as traffic statistics. Updates to this program are published regularly.

The fifth country is Australia. It uses the useful feature for drivers - the parking assistance system. The bottom line is in special monitors, which broadcast information about free spots. Along the lanes of the highway, special cameras are installed that photograph the number of the car, then the identification of the owner takes place, from the credit card of which the necessary fare is charged. This helps to avoid multi-kilometer traffic jams.

So, in comparison with foreign countries, the development of intelligent transport systems in Russia is in slow motion. Technological breakthroughs in the field of transport regulation are implemented locally. Probably, the main reason is the difficulty in organizing the unified management system on the scale of the huge country, characterized by an uneven, even often polar opposite level of technological equipment.

So, since the second half of the last century, experts have affirmed the understanding and realization that the potentialities of the industrial economy have practically exhausted themselves and are gradually ceasing to contribute to the growth of economic efficiency.

Since that time, methods, technologies, elements and systems of the intellectual economy begin to form, develop and spread on the global scale. This circumstance led to the 
emergence and development of intelligent management, which involves managing the system using the latest technology.

Interest in the study and implementation of intelligent transport systems is associated with the problem of organizing traffic, which in turn is caused by increasing motorization and urbanization. State activities in the field of traffic regulation are additionally motivated by national security priorities.

The study of experience with intelligent transport systems in Russia showed the local, point-like nature of the introduction of such organization methods. It seems that Russia is slowly but steadily following the road to technological progress in this area, as evidenced by the increased attention to the transport issue, which is now literally on the agenda of state policy.

Acquaintance with the experience of advanced countries in technological development illustrates the wisdom of intelligent transport management in these foreign countries. The key idea of this article is to recommend the use of the experience of foreign countries for the accelerated creation and implementation on Russian soil of traffic management methods tested by foreign countries. The key to successful traffic management is the quality realization of the potential opportunities provided by the latest digital technologies.

One of the cornerstones of the upcoming changes and the implementation of new technologies is smart transport that can move efficiently without direct human control. Such cars are called unmanned or self-driving. The unmanned cars unit in the single network, exchange information about the traffic situation with the control center and with each other. Of course, their distribution will completely change both the passenger transportation system and logistics schemes.

Every day new unmanned vehicles appear more and more. For example, the UBER, which was the passenger transportation company, tested unmanned vehicles in Toronto, San Francisco, Phoenix, Pittsburgh in 2017. This also makes the commitment to purchase twenty-four thousand Volvo cars, which will be available during between 2019 and 2021 . Special sensors, cameras and software will be installed on these machines. So, these tools make them unmanned.

Unmanned trucks are actively tested in Japan, and "Tesla" has already tested the new "TeslaSemi" self-driving trucks on American roads. Mass production of these machines will start in 2019. Also the delivery of goods with the use of unmanned aerial vehicles has already used in America.

Today digitalization is taking over the motor transport complex both in foreign countries and in the Russian Federation. So, road safety improving is designated as one of the strategic goals of the state's development by Decree of the President of the Russian Federation dated May 7, 2018 No. 204 "About the National Goals and Strategic Tasks of the Development of the Russian Federation for the Period until 2024".

The President noted among the measures aimed at realizing the task not only toughening the responsibility for violation of traffic rules and increasing requirements to the level of training, but also the use of the latest automated and robotic technologies for organizing traffic.

Several projects in this area have been launched in Russia. The unmanned "Matryoshka" bus manufactured by Volgabus was tested in 2017; the self-driving car of the domestic Yandex company was successfully tested in February 2018; KamAZ company presented the vehicle that can deliver goods under the control of artificial intelligence. According to the statement of the "Avtodor" company, the design of roads for unmanned vehicles is already conducted in Russia.

It becomes obvious that in the nearest fu- 
ture we will be surrounded by cars and vehicles of all kinds and forms, which will be independent from the person. So, it can be run without the driver.

The huge amount of electronics is installed in unmanned vehicles, from speedometers and barometers to powerful on-board computers, as well as several dozen complex systems that are interconnected, including, for example, braking and acceleration systems. Today, cars, which can independently stay on the road lane, adjust the speed and direction of movement, are also widespread.

To increase efficiency, unmanned vehicles constantly collect information about the owner and his surroundings: place of residence, work, daily and weekly routine. This information risks getting to the attacker and can be used to commit an illegal act.

All control is carried out through the computer, which gives great opportunities to attackers. If they gain control over the braking system, they will be able to transmit the command to suddenly stop the car at high speed on the busy road, which will almost inevitably lead to an accident where someone could die or be injured.

Using the access to the acceleration system, the attacker can accelerate the car to high speed at the right time and direct it to one of the objects of increased danger, for example, to the gas station, or knock down a person or run over the crowd of people at the extreme speed.

So, the potential for harm through driving the unmanned vehicle is extremely wide. This can entail both financial and human losses, cause serious damage to the infrastructure and the economy as a whole.

Consequently, the vulnerability and susceptibility of this category of vehicles to cyber attacks should become the most important problem and the main issue in the process of implementation of the unmanned vehicles.

As an example, let's take a look at hacking
Jeep cars by the "FiatChrysler Automobiles (FCA)" company in July 2015. Hacking was demonstrated by Charlie Miller and Chris Valasek, two researchers in the field of information security. Using the laptop and mobile phone, they took control of the "JeepCherokee", while journalist Andy Greenberg forced vehicles into the ditch.

This is not an exceptional case. The researchers hacked also 1.4 million cars and trucks. Because of the vulnerability of these cars and trucks the "FiatChrysler Automobiles" company recalled defected cars after the publication of the article.

Thus, the problem of the integrity and security of the information system of unmanned vehicles is acute.

The risk of interference in the operation of the unmanned vehicles appears at the initial stage of its production, however the attention to safety at the enterprise and the control of the technological process are not always paid enough. Also the process of development, debugging and testing of software that is loaded into the on-board electronics cannot be ignored.

Most cyber attacks are carried out using wireless technology. Almost all unmanned vehicles are equipped with the large number of different wireless means for communication with the outside world. For example, WiFi, Bluetooth, cellular, radio, GPS, V2V (protocol for communication between unmanned vehicles) are the incomplete list of means, which allow the attackers influence on technology.

The situation is complicated by the fact that all drones and autonomous vehicles use GPS to navigate, which is extremely unsafe. This widely used civil signal is not encrypted.

The University of Texas has conducted studies that have shown that these signals can be faked. The attacker is able to change the direction of movement by entering the data of his route. This is the so-called "GPS Spoofing 
attack" - an attack that in some cases can trick the GPS receiver into transmitting the signal that disguises itself as the true GPS signal, but transmits its data. Spoofing is also used in everyday life. For example, residents of Moscow pay attention to the fact that GPS navigation is malfunctioning in the city center near the Kremlin.

Also, do not forget that any vehicle is not insured against technical malfunctions and failures, untimely response to changes in road conditions. The unmanned vehicles are no exception. So, the already mentioned company "UBER" was forced to interrupt testing of unmanned vehicles due to the incident (the UBER car knocked the woman to the death). The car moved offline under the remote control of the operator. It was the first-ever human death in the accident with the unmanned vehicle on public roads, according to The New York Times. Later it became known that the woman had crossed the road on the bicycle outside the pedestrian crossing in the dark.

\section{CONCLUSION}

Thus, it is now becoming quite obvious that it is necessary to focus not only on the functionality and technical characteristics of the unmanned vehicle, but also, how to protect it from unauthorized access, which could entail serious consequences, as well as provide for the possibility of prompt response to changing traffic conditions, to act not only according to the rules of the road, but also according to the situation.

Intelligent transport system uses innovative developments in the modeling of transport systems and regulation of traffic flows, qualitatively increasing the level of interaction of traffic participants in comparison with conventional transport systems.

A promising area in automotive electronics today is the creation of a unified service in- formation and telematic platform. It is assumed that this system will concentrate all data on vehicles and road infrastructure from various state and private information systems. In the future, this platform may turn into a base for organizing unmanned automobile traffic.

The potential of a unified intellectual transport system is unlimited. It allows you to: ensure efficient data exchange between all interested organizations; to regulate the work of traffic lights and other technical means of traffic control and adjust the mode of operation of these means in accordance with the actual traffic situation; reduce road deaths by increasing the speed of response to a traffic accident; to ensure the unimpeded movement of special vehicles to the place of a road transport or other accident; inform drivers of their violation of the rules of the road and the operation of the vehicle, as well as the current and short-term forecast of the state of traffic conditions; automatically record facts of violation of traffic rules to identify and punish perpetrators; increase the throughput of roads by regulating traffic flows, etc.

Despite the identified problems, digitalization will have the constant upward trend. It is necessary to pay special attention to security in the functioning of artificial intelligence at the legislative level, for example, clearly state its legal status, and also stipulate the terms of liability in case of harm.

\section{REFERENCES}

ARKHIPOV V. V., NAUMOV V. B. On some issues of the theoretical foundations of the development of legislation on robotics: aspects of will and legal personality. Law. Moscow: Publishing House. Law, 2017, 5.

BELYAEV K. M., ROMANOV A. A. Cyber security of unmanned vehicles. Technical 
and technological problems of service. St. Petersburg: Publishing House St. Petersburg State University of Economics, 2018, 2.

BEVZENKO R. S. How I defeated a forensic robot lawyer. URL: https://zakon.ru/blog/ 2018/05/21/kak_ya_pobedil_sudebnogo_rob ota-yurista_i_pochemu_eto_budet_dlitsya_ nedolgo\#comment_464408 (accessed 01.10. 2019)

CHOPRA S., WHITE L. Artificial Agents Personhood in Law and Philosophy. URL: https://philpapers.org/rec/CHOAA (accessed October 1, 2019).

DUGGAL P. Artificial intelligence law. 2017.

GREENMAN +: Site ONE.MOTORING. URL: http://www.onemotoring.com.sg/pub lish/onemotoring/en/on_the_roads/traffic_ management/green_man_plus.html (accessed: 09/10/2019)

ITS initiatives in Japan. Website of the Ministry of Land, Infrastructure, Transport and Tourism of Japan. - URL: http://www.mlit. go.jp/road/ITS/pdf/ITSinitiativesinJapan.pd f (accessed: 10/09/2019)

Junction Electronic Eyes (J-Eyes): Website One. - URL: https://www.onemotoring.com. $\mathrm{sg} /$ content/onemotoring/en/on_the_roads/t raffic_management/intelligent_transport_sys tems/junction_eyes.html (accessed 09.10. 2019)

KOSTOMAROVA V. V. Foreign experience in implementing intelligent transport systems (ITS). Actual problems of the humanities and natural sciences. 2016, 4-1.

KOVALENKO K. E., ROZENTSVAIG A. I., GUBAREVA A. V. International terrorism and international cyberterrorism. Quidinvestigacion ciencia y tecnologia. 2018, 2 (SI).

Legal battle: a robot from Megafon vs Roman Bevzenko. URL: https://pravo.ru/lf/story/ 202675/ (accessed October 1, 2019)

MOSKALEVA O. The dangers posed by digitalization. Housing law. Moscow: Pub- lishing House of Human Resources, 2017, 10. KHLEBNIKOV P. Digitalization of law as a consequence of the digitalization of life. Housing law. Moscow: Publishing House of Human Resources, 2017, 9.

On national goals and strategic objectives of the development of the Russian Federation for the period until 2024: Decree of the President of the Russian Federation of May 7, 2018 No. 204.

Smart transport: New challenges to information security. URL: https://habrahabr.ru/ company/pt/blog/302194/ (accessed October 1, 2019)

UK cyber-security expert warns self-driving cars could be hacked. URL: http:/ / mashable. com/2014/11/25/driverless-cars-uk/\#MYyai a090iqc (accessed 10/01/2019)

VDOVIN R. A., ROZENTSVAIG, A. I., KOVALENKO, K. E., Kovalenko, N. E. Defects of terminology in law and technique. Religacion-revista de ciencias sociales y humanidades. 2019, 4(18) SI.

What is the danger of a robomobile? URL: https://www.kaspersky.ru/blog/driverlesscars-dangers/12956/ (accessed 01.10.2019)

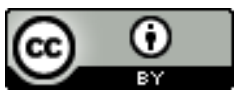

License information: This is an openaccess article distributed under the terms of the Creative Commons Attribution License, which permits unrestricted use, distribution, and reproduction in any medium, provided the original work is properly cited.

Article received on November 10, 2019.

Evaluated November 15, 2019.

Accepted on November 15, 2019.

Published on November 21, 2019.

\section{How cite this article (ABNT):}

KOVALENKO, Kseniya E.; STATSENKO, Daria A.; PECHATNOVA, Yulia V. The legal regulation of digitalization of some areas of public life in modern theory of State and Law. Estação Científica (UNIFAP), Macapá, v. 9, n. 2, p. 55-62, apr./jun. 2019. 